\title{
Multiple traps compromise the sustainability of most livestock farmers in Sierras del Este, Uruguay
}

\author{
Ismael Díaz ${ }^{1}$ (D) Néstor Mazzeo ${ }^{2,3}$ - Marcel Achkar ${ }^{4}$ \\ Accepted: 14 January 2020 / Published online: 29 January 2020 \\ (C) INRAE and Springer-Verlag France SAS, part of Springer Nature 2020
}

\begin{abstract}
Livestock system structure is a relevant factor in determining the decision-making processes and the initiatives to reduce the vulnerability to external drivers. The definition of livestock stocking density (LSD) is a key factor as it determines the sustainability of the activity. LSD adjusted to grassland productivity in space, and time has been advocated by researchers and policy makers. However, most livestock farmers fail to adjust the LSD, and therefore, their vulnerability increases. This study explored the hypothesis that productive decisions in livestock systems include information that reinforced the vulnerability. The main objective of this study was to evaluate vulnerability of livestock farmers through the information that guides the decision-making process. We analyze information based on which farmers define the LSD, focusing on the relationship between the farmers' perception of grassland productivity, the main reasons for their decisions, and grassland productivity using remote sensing techniques. The research strategy integrated interviews with farmers regarding LSD and grassland aboveground net primary productivity estimates. The results showed that $77 \%$ of the farmers use LSD higher than the carrying capacity, although $66 \%$ of them do so knowingly. Consequently, most farmers are in a situation of high vulnerability, especially to rainfall regime variability. Almost all farmers are affected by at least one trap: poverty, rigidity, or gilded. A clear contradiction is identified between the farmer's decisions and the current recommendations suggested by researchers and public policy, which are mainly explained by the farmers' optimism. Results highlight the access to information as a great barrier to the adoption of adaptive strategies. We show for the first time the main traps and its causal associated mechanisms, which limit the decision-making of Uruguayan livestock farmers. The proposed framework can be used in other agricultural systems to identify barriers and traps, as the first step toward increasing agroecosystem sustainability.
\end{abstract}

Keywords Natural grasslands $\cdot$ Livestock $\cdot$ Campos $\cdot$ Over-stocking $\cdot$ Traps $\cdot$ Vulnerability $\cdot$ Cattle

Ismael Díaz

idiaz@fcien.edu.uy

Néstor Mazzeo

mazzeobeyhaut@yahoo.com

Marcel Achkar

achkar@fcien.edu.uy

1 Laboratorio de Desarrollo Sustentable y Gestión Ambiental del Territorio. Instituto de Ecología y Ciencias Ambientales. Facultad de Ciencias, Universidad de la República, int 173. Igua 4225, CP 11400 Montevideo, Uruguay

2 Departamento de Ecología y Gestión Ambiental. Centro Universitario Regional del Este. Facultad de Ciencias, Universidad de la República, Maldonado, Uruguay

3 Instituto SARAS, Bella Vista, Maldonado, Uruguay

4 Laboratorio de Desarrollo Sustentable y Gestión Ambiental del Territorio. Instituto de Ecología y Ciencias Ambientales. Facultad de Ciencias, Universidad de la República, Montevideo, Uruguay

\section{Introduction}

Grassland management is a key factor for maintaining the sustainability of livestock production systems (Kemp and Michalk 2007). These agroecosystems are highly complex and constantly affected by external climatic and non-climatic drivers. Additionally, they are usually affected by traps (system configurations), which hinder and/or limit favorable trajectories. Traps are adverse, undesirable, persistent, and self-reinforcing situations (Haider et al. 2018), which prevent beneficial transformations (Carpenter and Brock 2008) and limit the ability of a system to adapt to external events and reduce the vulnerability, understood as the degree of susceptibility and the lack of capacity to deal with the negative impacts caused by external events. Three types of traps are predominant. The rigidity trap, determined by a highly connected system, minimally diverse (in socioeconomic and/or natural components), and inflexible system, generates a homogenous system with low innovation capacity (Gunderson and 
Holling 2002). Poverty traps, refer to unsustainable situations reinforced through feedback between social and ecological processes (Haider et al. 2018), wherein people are impoverished by circumstances beyond their control (Gunderson and Holling 2002) and lack resources or the ability to focus on ideas or to connect actors and key agents to improve the system (Westley et al. 2006). Lastly, gilded traps refer to actions derived from economically attractive opportunities outweighing potential risks but generating important and negative ecological and socioeconomic impacts (Steneck et al. 2011). The application of traps (and the connections with the adaptive cycles theoretical frameworks) to agricultural system is very recent, highlighting the approaches focused on poverty traps and their link with development and well-being (e.g., Tittonell 2014; Haider et al. 2018).

The decisions that livestock farmers make about their farms are usually affected by well-established traps, which in turn may help to consolidate new traps, thereby putting them in a situation of high vulnerability to biophysical and economic external drivers and internal control factors (Díaz et al. 2018). Livestock familiar farmers make complex decisions, which can only be understood based on the specific objectives and situation of each farmer, albeit with a common decision-making pattern, either to keep the production system in a state of persistence or to move it toward a desired situation. Each situation is usually affected by external drivers and factors, sensitivity (degree to which a system is affected), and adaptability (ability of a system to adjust to external drivers) of the system, in addition to various traps, which hinder and interfere with the operation of the production system. Traps have a set of feedbacks that ensure their persistence over time (Carpenter and Brock 2008) and determine (and are determinate by) the level of sensitivity and adaptation of the systems. The trajectory and dynamics of livestock farmers, independently the situation they intend to achieve or maintain, are constrained by a set of traps.

The livestock carrying capacity (LCC) is key in extensive animal husbandry management under grazing because it is closely linked to the profitability and sustainability of the activity (Foran and Stafford 1991; McKeon et al. 2009). Imbalances between LCC and livestock stocking densities (LSD) may lead to underutilization of resources, which triggers loss of profits, or conversely, and most often, to overutilization of resources, which causes serious problems in natural resources (grasslands, soils, and water) and consequently reduced performance (Zhang et al. 2014). Stocking density can be considered as an output variable of the grazing system according to what was stated by Do Carmo et al. (2016), However, in vulnerability assesmente stocking density is an input variable because it feedbacks and conditions the performance of the systems. Mckeon et al. (2009) emphasize the benefits of maintaining forage use levels associated with LSD adjusted to grassland conditions, highlighting reduced impacts during droughts, reduced need for selling livestock in times of low prices, decreased need for resorting to dietary supplementation, decreased feeding problems, improved livestock conditions and reproductive performance, and improved grassland quality. Studies focused on the definition of LCC have mainly evaluated the relationship between livestock intake and grassland productivity (e.g., McKeon et al. 2009; Zhang et al. 2014). For estimating intake, the main strategy has been the definition of the biomass intake of different herbivores (AFRC 1993; INIA 2012). For estimating productivity, studies initially used biomass harvests and, subsequently, empirical models based on remote sensing techniques. Currently, the most utilized model is Monteith's Model (Monteith 1972), which establishes that the aboveground net primary productivity (ANPP) is determine by the fraction of absorbed photosynthetically active radiation (fPAR), the incident photosynthetically active radiation (PAR), and the radiation use efficiency $(\varepsilon)$.

In Uruguay, the intake evaluation in general has been associated with the estimation of livestock units (LU) which is a parameter of equivalence on the biomass energy consumption by herbivores (INIA 2012), and the Monteith's Model has been widely used to estimate ANPP by researchers (e.g., Baeza et al. 2011; Gallego et al. 2017; Díaz et al. 2019) and by the agricultural institutions (e.g., MGAP, INIA). Despite these advances in the generation of information, Uruguayan livestock farmers usually do not use this information to make their decisions. However, $50 \%$ of Uruguayan livestock farmers use stocking density to make decisions, and $63 \%$ know or at least heard about the concept (Lindemann et al. 2013). Gutierrez and Modernel (2011) show in a case study that producers decide to resort to over-stocking, and the reasons for their decision are contradictory to those proposed by technicians. This situation, on the one hand, questions information based on which decisions are made and, on the other hand, highlights other sources of information, such as field experience and perceived grassland performance as key management inputs.

The relationship between perception and technical estimates of grassland productivity can offer three possibilities: agreement, as the first scenario; a difference in which the perceived grassland productivity is higher than the estimate; and, finally, a difference in which the perceived grassland productivity is lower than the estimate. In the second scenario, the livestock farmer identifies a higher potential in the grasslands than the estimate (optimistic estimate), and in the third scenario, grassland productivity is lower than the estimate (pessimistic estimate). The possible impacts from these scenarios are clearly different; the second scenario is most likely to be adversely affected by negative biophysical and economic impacts. The adjustment of the stocking density is key in times of drought in which productivity decreases and the forage deficit worsens. This is particularly relevant in Uruguay, especially in Sierras del Este (Fig. 1), one of the regions of the country most vulnerable to climate variability and drought (Díaz et al. 2019). However, livestock farmers usually do not adjust stocking 
density structurally (Díaz et al. 2018), adjusting it only in critical times. This adverse situation was also identified by Bartaburu et al. (2009) and in other regions of the country, highlighting its negative impacts.

Decision-making processes in Uruguayan livestock systems have been broadly analyzed, focusing mainly in the framework of technology adoption and technological change (e.g., Mondelli and Picasso 2001; Carriquiry and Fernandez 2004). However, the decision-making process in agricultural systems integrates a complex set of decisions and dimensions that demands new approaches and systemic analysis. In this context, the following key questions arise. Based on what information and on what objectives do livestock farmers define stocking density? Is it possible to identify traps that affect the livestock farmers' decision-making and vulnerability? Does the incidence of traps vary by type of farmer? The main objective of this study was to evaluate the vulnerability of livestock farmers through the information that guide the decision-making process. The agreement between the perception and technical measurements of ANPP of grasslands was assessed, identifying the livestock farmers most vulnerable to unsuitable grassland management. Finally, the article provides a set of reflections to contribute to the design of public policies linked to reducing the vulnerability of livestock farmers.

\section{Methods}

\subsection{Study area}

The study area is located in Sierras del Este region (Uruguay) and includes the Barriga Negra and Polanco stream basins
(72,600 ha) (Fig. 2). The climate is temperate subtropical, with annual rainfall of $1100 \mathrm{~mm}$ without a dry season. The dominant ecosystems are natural grasslands and natural forest. The dominant soils are argiudolls (75\%) and lithosols (17\%), and more than $70 \%$ of the soils are moderately rocky. Hills dominate the topography (83\%) and the average surface slope is $8 \%$.

In the study area are located 100 farmers who practice an extensive livestock mostly over natural grasslands. The average extension of the farms is 150 ha, but farmers with less than 20 ha and a farm size of over 1300 ha can also be found. The vast majority of farmers implement a mixed livestock production system (bovines and ovine), but they have a bovine production as their main activity and sheep farming marginally. The average livestock stocking density (LSD) found in the study area is 0.79 LU per hectare (Díaz et al. 2019).

\subsection{Primary production and livestock carrying capacity estimations}

Monteith's Model was utilized (Monteith 1972) (Ec 1)

$$
\begin{gathered}
\text { Ecl. ANPP }\left(\mathrm{kg} \mathrm{DM} \cdot h a^{-1} \cdot y^{-1}\right)=f P A R\left(M J \cdot h a^{-1} \cdot y^{-1}\right) \\
\times P A R \times \varepsilon\left(\mathrm{kg} D M \cdot M J^{-1}\right)
\end{gathered}
$$

where fPAR is the fraction of absorbed photosynthetically active radiation, PAR is the incident photosynthetically active, and $\varepsilon$ is the radiation use efficiency.

According to the approach applied by Díaz et al. (2019), the fPAR was estimated using the normalized difference vegetation index (NDVI) of the MODIS data series for the periods 2000 2017, because NDVI is positively related to PPAR from vegetation and therefore to primary productivity. PAR was estimated from the spatial interpolation (kriging) of the values of sun hours/

Fig. 1 Livestock system in the Barriga Negra stream basin, Sierras del Este region, Uruguay. In this farm, the farmer implements a mixed livestock production system (bovines and ovine) but with predominance of bovines

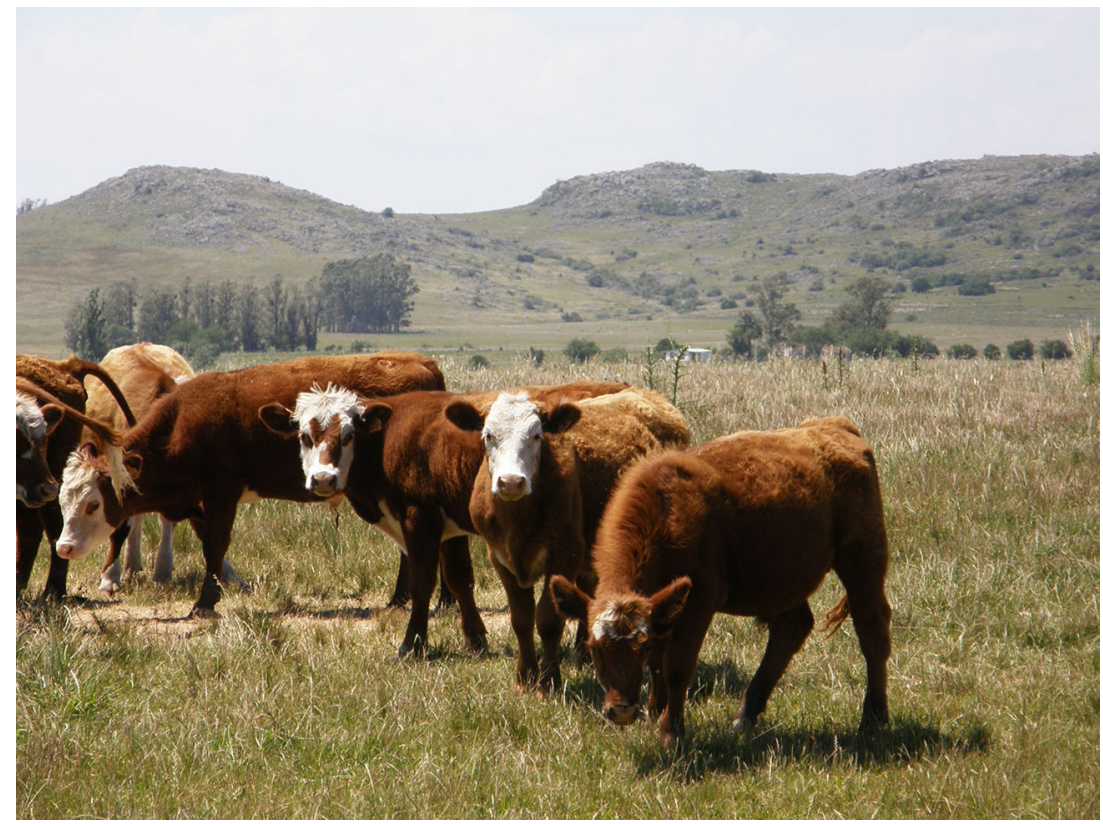




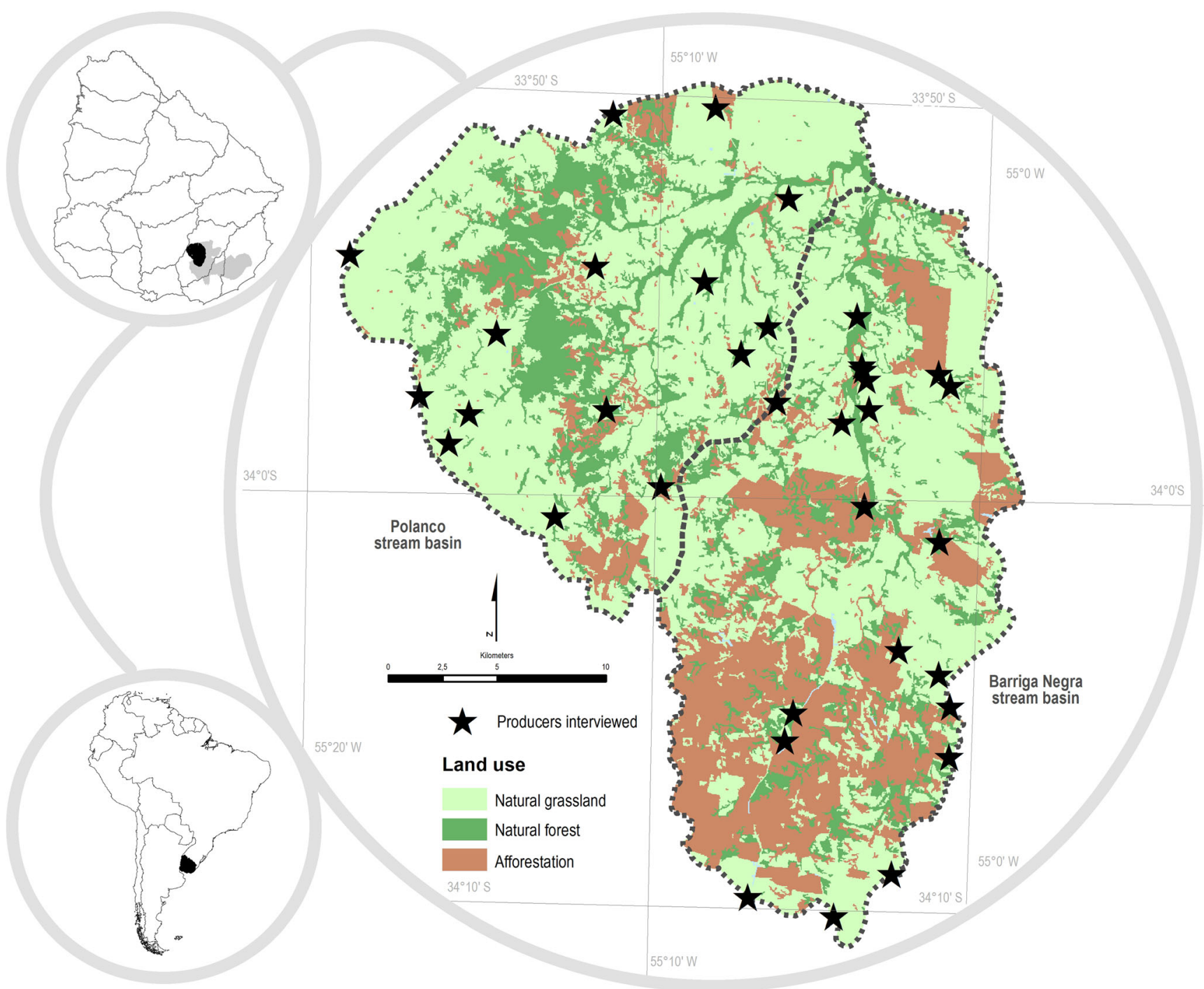

Fig. 2 Study area. Dominant land cover and localization of interview livestock farmers

day of the nearest meteorological stations (Carrasco y Treinta y Tres, located $100 \mathrm{~km}$ southwest and $60 \mathrm{~km}$ northeast respectively of the study area). The data was provided by Instituto Nacional de Investigación Agropecuaria (INIA). Finally, $\varepsilon$ was obtained from Gallego et al. (2017) who proposed $\varepsilon=0.36 \mathrm{~kg}$ DM. MJ-1 for grasslands of the same region.

LCC was estimated from the ANPP, the annual individual requirement $(\mathrm{AIR}=$ requirements in dry matter that a $1 \mathrm{LU}$ needs) and the harvest index ( $\mathrm{HI}=$ consumable percentage). This method was used by Gallego et al. (2017) for an area of the same study region, who assumed an AIR $(1 \mathrm{LU})=2774 \mathrm{~kg}$ $\mathrm{DM}$ according to a $50 \% \mathrm{HI}$.

ANPP and LU information was georeferenced and systematized at the farm scale of each farmer.

\subsection{Evaluation of the perception of productivity and stocking density}

In-depth, semi-structured interviews were conducted with 35 livestock commercial farmers. The interviews were conducted between 2015 and 2018, visiting the farmers in their farms, in different years and seasons. This strategy allowed validating the information collected in previous interviews. The farmers were asked about social and productive aspects; perception of grasslands productivity; about whether the LSD was high, low, or adjusted to the grassland productivity; and finally about the possibility of adjusting it. Through this flexible technique, livestock farmers reported their stocking density, decision-making process, and the strategies used for livestock management, and, finally, 
they valued the forage productivity (as indicator to the grasslands productivity) of their farms. Thus, the livestock farmers' perception of grassland productivity was rated from 1 (very low productivity) to 5 (very high productivity) based on the historicalpersonal context of each farmer and the local context. In addition, livestock farmers were asked about the performance of their fields in periods of normal rainfall and drought. The relationship between these responses was evaluated using the Spearman's rank correlation nonparametric test $(p<0.05)$.

Stocking density was evaluated during the interviews and was systematized at the farm scale. LU were estimated using equivalent parameters developed by the INIA (2012). In this proposal, a weighting coefficient is assigned, depending on the species (bovine, sheep, or equine) and the category (age of the herbivore), which allows a comparable measure about consumable biomass (equivalent to the requirements of a $380 \mathrm{~kg}$ cattle). In this way, the LSD of each farm corresponds to the ratio between the weighted sum of the herbivores and the grassland area.

\subsection{Traps}

Traps have been identified as system configuration which interferes with the progression of adaptive cycles, and this framework is applied for the identification of phases within the cycle and for their evaluation (Gunderson and Holling 2002; Carpenter and Brock 2008). Adaptation is not a linear process, covertly is it the outcome of progression of different auto defined and reinforced actions. The framework of adaptive cycles allows to understand the change in socioecological systems. In addition, it is used to understand how persistence and transformation coexist in these systems and in what contexts the transformations occur (Cosens and Gunderson 2018). Owing to the complexity of the relationships in this framework and to difficulties in its application to any context, this study focused on the link between traps and decision-making in livestock farms. Accordingly, the traps were defined as a function of a key decision made by livestock farmers (the stocking density) and the information and objectives that guide that decision. This information was collected during the interview process, in which farmers narrated their production history, the decisions taken, and the impacts of these decisions. The occurrence of poverty traps was determined when livestock farmers resorted to over-stocking for lack of resources and/or because they were prevented (for whatever reason) from adjusting the stocking density. Moreover, poverty traps were defined when livestock farmers identified, according to the configuration of their livestock production system, over-stocking as the only option to avoid compromising their profitability. The occurrence of gilded traps was determined when the reason for over-stocking was a beneficial and strictly economic opportunity for livestock farmers. Lastly, rigidity traps were defined when the reason for over-stocking was the lack of flexibility in adopting viable strategies for adjusting the stocking density and/or when differences were found between perceived grassland productivity and ANPP.

In summary, the traps are defined and provided with feedback by the interactions between the decisions taken by the producers and the structure of the farm (which in turn has conditioned the occurrence of the traps) and determine the vulnerability to external drivers. The vulnerability control of farmers implies the reduction of the exposure and increases the ability to respond to external events. The inability to respond to external events compromises the sustainability (understood as a multi-dimensional attribute, biophysical, economic, and productive). According to this, sustainability is operationalized as the permanence of the farm and the farmers in the medium and long term.

\section{Results and discussion}

Almost all livestock farmers were affected by at least one trap, which compromises the sustainability of the activity. Most livestock farmers used a LSD that clearly exceeded the LCC. These discrepancies question the information based on which livestock farmers make their decisions, highlighting divergence with the promoted strategies by Uruguayan agricultural institutions, and ultimately, they question the objectives and economic needs of livestock farmers. In particular, some traps systematically forced livestock farmers into making a set of decisions that increased their vulnerability to external climatic and economic drivers, due to feedback processes of the traps and their status as a regime with capacity to remain over the time.

Table 1 Farm values (average, minimum, maximum, and coefficient of variation $(\mathrm{CV})$ ) of grassland aboveground net primary productivity (ANPP), livestock stocking density (LSD), and livestock carrying capacity (LCC)

\begin{tabular}{lllll}
\hline & Average & Minimum & Maximum & CV \\
\hline ANPP (kg DM. ha $\left.{ }^{-1} \cdot \mathrm{y}^{-1}\right)$ & 3922 & 3326 & 5356 & $13 \%$ \\
LSD $\left(\mathrm{LU} . \mathrm{ha}^{-1}\right)$ & 0.88 & 0.6 & 1.1 & $18 \%$ \\
LCC $\left(\mathrm{LU} . \mathrm{ha}^{-1}\right)$ & 0.71 & 0.47 & 0.83 & $13 \%$ \\
\hline
\end{tabular}




\subsection{Productivity perceptions vs productivity estimations}

The average ANPP and LCC for the study area presented, among year (2000-2015), low variability (Table 1). Conversely, ANPP and LCC presented high variability within the study area (Fig. 3); the farm with the highest values was 1.77 times more productive than the one with the lowest values. In general, livestock farmers have a positive perception of the productivity of their grasslands. In total, $49 \%$ of livestock farmers reported that their grasslands have high productivity, 37\% medium and the remaining 14\% low (Fig. 4) (Table 2). Monthly and annual averages of grassland ANPP were not associated with perceived grassland productivity throughout the study period $(p>0.05)$ except for the months of severe drought $(p<0.05, \mathrm{rS}=0.1$, statistically significant but very weak).

Differences between perception and estimation could be related to two possible causal mechanisms. The first mechanism refers to conceptual problem and also to possible deficiencies of techniques currently used to estimate productivity. Despite major improvements in recent years, large-scale access to information, mainly on the radiation use efficiency of each farm, remains a considerable limitation, in addition to the set of assumptions (the growth rate is a reasonable estimator of PPNA, and there are a similar composition of grasslands at similar sites) used for its estimation which have been identified for local conditions by Baeza et al. (2011). On the other hand, and despite the fact that national scientific contributions agree on the potential of this approach for estimating the productivity of natural grasslands in Uruguay, the period analyzed (18 years) requires caution because the patterns observed can be part of a cyclical trend of higher temporal scale. Access to satellite information is presented as a restriction and, therefore, limits a deeper analysis of the data.

The second mechanism suggests that livestock farmers fail to correctly estimate the potential of their grasslands. The focus that farmers put on livestock instead of grassland (Bartaburu et al. 2009) could explain this situation. As the productivity levels identified in this study are similar to those recorded for the region (Bartaburu et al. 2013), differences between estimation and perception suggest overestimation of perceived grassland productivity. Therefore, the discrepancy between perceived and

Fig. 3 Usable grassland aboveground net primary productivity (ANPP) as a function of livestock stocking density (LSD); the line $(\mathrm{y}=\mathrm{x} / 2774)$ indicates the mean livestock carrying capacity (LCC) for a $50 \%$ harvest index and for a consumption per LU of $2774 \mathrm{~kg}$ DM per year, and the dotted lines indicate intervals $\pm 10 \%$ of LCC. The plot starts from $\mathrm{x}=0.4$ and from $\mathrm{y}=1200$ to facilitate figure interpretation

\section{Usable ANPP and stocking density}

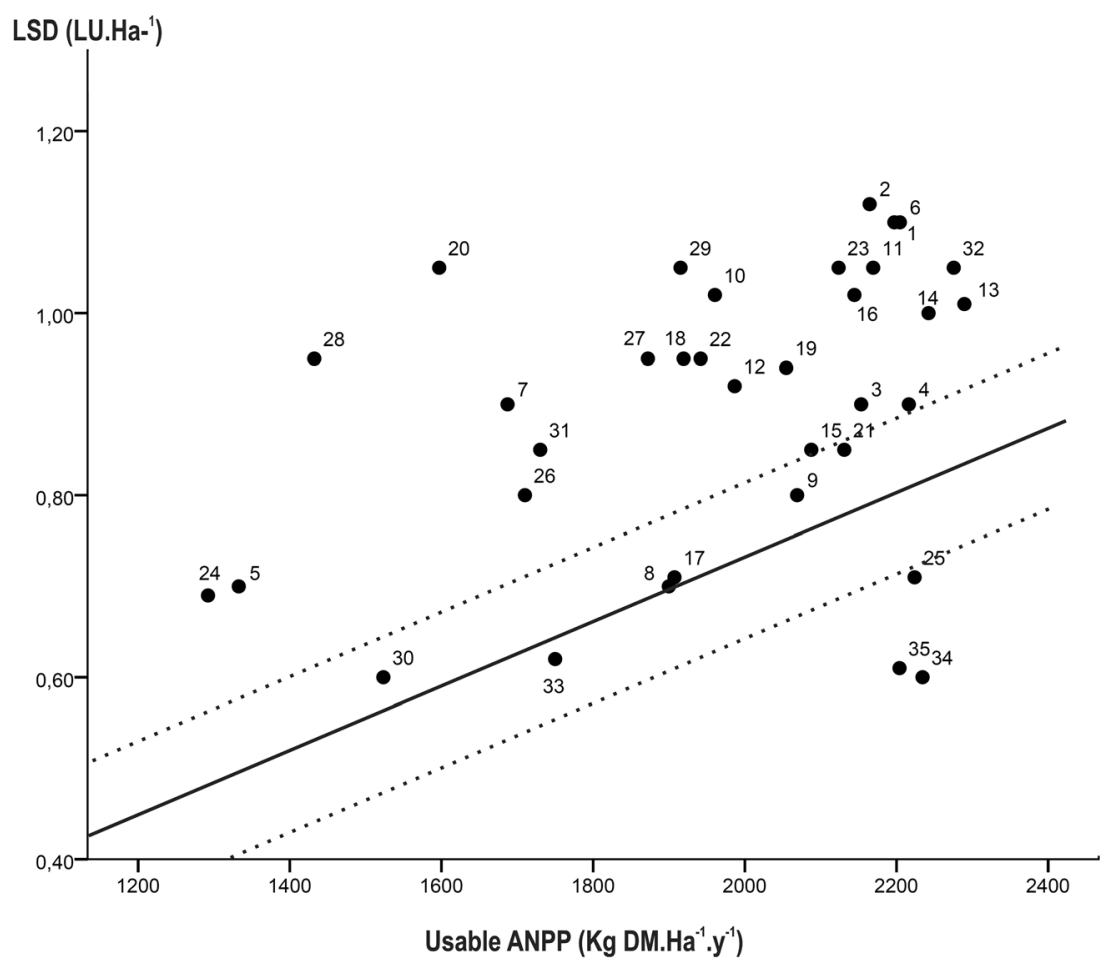


Fig. 4 Perceived grassland productivity (qualitative variable from 1 that is very low productivity to 5 very high productivity) as a function of stocking density. The vertical line $(x=3.5)$ indicates the start of the perception of high productivity, the solid horizontal line $(y=0.71)$ indicates the mean livestock carrying capacity (LCC), and the dotted lines indicate minimum and maximum LCC in the study area

\section{Perceived productivty and stocking density}

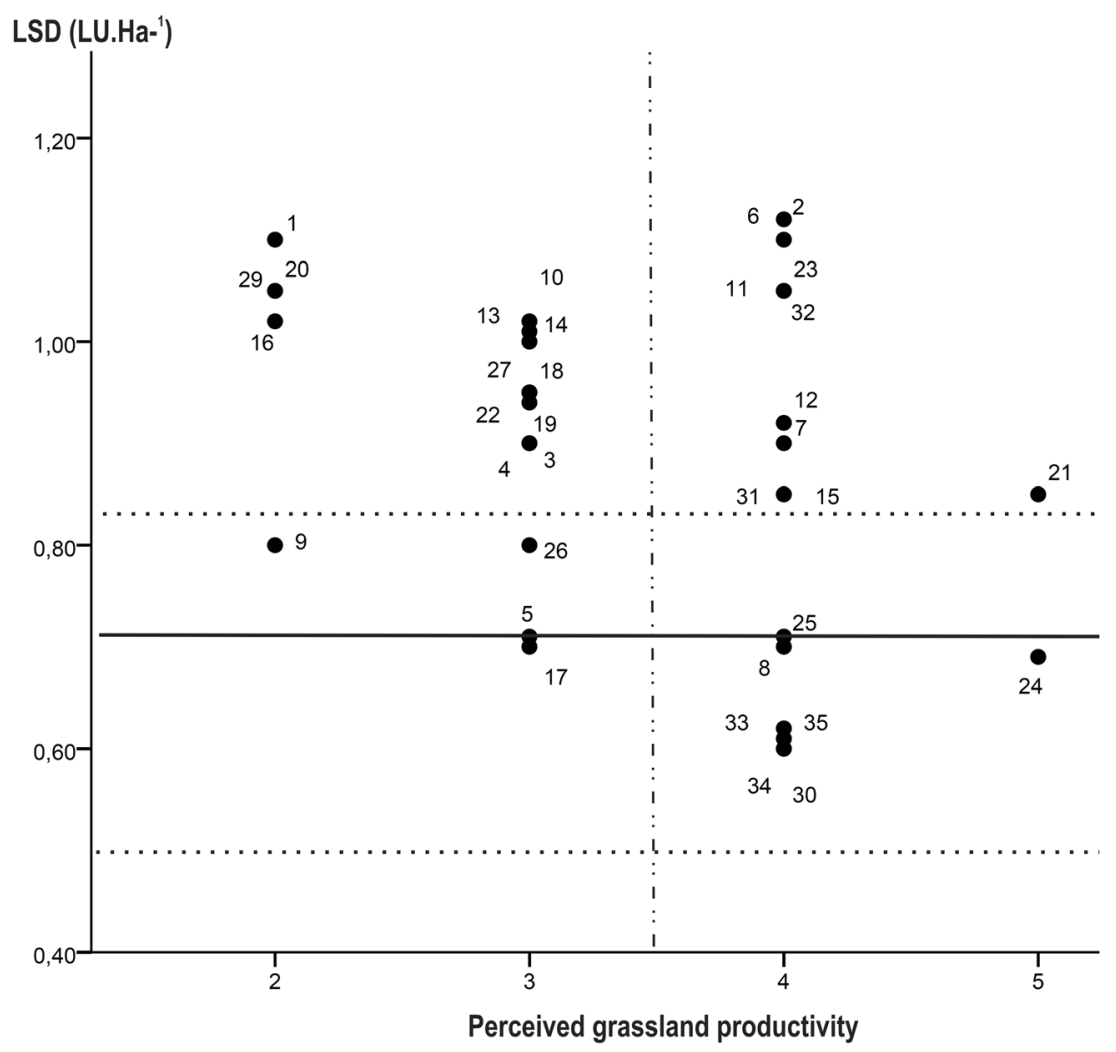

estimated productivity generates a scenario of high vulnerability of livestock farmers, which increases with this difference. The identification of livestock farmers in this situation is relevant to implementing measures for improving the knowledge of each livestock production system. It is important to note that many farmers have observed and valued grassland productivity for more than 18 years. However, these evaluations were not carried out systematically, and there are also no systematized records to incorporate into this analysis. Access to the information generated in this study in synergy with the livestock farmers' experience may help improve farm management. Strengthening information exchange relationships between livestock farmers and increasing access to technical assistance and to information could improve the knowledge of and subsequent management of processes which define the main controlling factors of livestock production systems (Díaz et al. 2018). Group learning and coinnovation strategies could yield positive results as reported for other key decision in livestock systems of the region and for other areas of the country (Albicette et al. 2017).

\subsection{Over-stocking: Strategy or necessity}

The LSD average for the study area were $0.88 \mathrm{LU} / \mathrm{ha}$. About $11.5 \%$ of livestock farmers reported a LSD lower than to the LCC, $11.5 \%$ around the LCC (equal or little higher than the LCC), and the remaining $77 \%$ at least $10 \%$ higher than the LCC (Table 2). Of the livestock farmers with a LSD higher than the LCC, $76 \%$ confirmed that grassland was the only source of food, $14 \%$ sometimes used dietary supplements, and the remaining $10 \%$ used dietary supplements. In total, $37 \%$ of livestock farmers used a high stocking density in grasslands with low perceived grassland productivity, $22 \%$ a high stocking density in grasslands with high perceived productivity, and $11 \%$ a low stocking density in grasslands perceived with high productivity (Fig. 4). The remaining $20 \%$ of livestock farmers used a stocking density adjusted to their perceived grassland productivity. Of the livestock farmers whose perceived grassland productivity was higher than that of the LCC, $50 \%$ perceived that their grassland had a very high productivity and that they could even increase the stocking density (e.g., farmers 21, 7, and 6). Of the livestock farmers whose perceived grassland productivity was similar 
Table 2 Summary of the status of each livestock farmer regarding farm area (ha), livestock stocking density (LSD), usable grassland aboveground net primary productivity (UANPP), livestock carrying capacity (LCC), difference between LCC-LSD, LSD adjustment perception by farmers (P-LDS) (Yes farmers know the stoking density is

perception by farmens (P-LDS) (Yes fammens know the stoking density is

exceeded; No they do not know it), LSD adjustment (A-LDS), relationship between perceived grassland productivity and ANPP, relationship between perceived grassland productivity and LSD, reason for over-stocking, trap(s) affecting the livestock farmer ( $P$ poverty trap, $R$ rigidity trap, $G$ gilded trap), and main mechanism for the trap(s)

\begin{tabular}{|c|c|c|c|c|c|c|c|c|c|c|c|c|}
\hline $\begin{array}{l}\text { Producer } \\
\#\end{array}$ & $\begin{array}{l}\text { Farm } \\
\text { area } \\
\text { (ha) }\end{array}$ & $\begin{array}{l}\text { LSD } \\
(\mathrm{LU})\end{array}$ & $\begin{array}{l}\text { UANPP } \\
\text { (DM. } \\
\mathrm{ha}^{-1} \\
\mathrm{y}^{-1} \text { ) }\end{array}$ & $\begin{array}{l}\text { LCC } \\
\text { (LU) }\end{array}$ & $\begin{array}{l}\text { LCC- } \\
\text { LSD } \\
(\mathrm{LU})\end{array}$ & $\begin{array}{l}\text { P- } \\
\text { LSD }\end{array}$ & A-LSD & $\begin{array}{l}\text { Perception/ } \\
\text { ANPP } \\
\text { relationship }\end{array}$ & $\begin{array}{l}\text { Perception/ } \\
\text { LSD }\end{array}$ & $\begin{array}{l}\text { Over- } \\
\text { stocking } \\
\text { reason }\end{array}$ & $\operatorname{Trap}(\mathrm{s})$ & $\begin{array}{l}\text { Main mechanism for } \\
\text { the trap(s) }\end{array}$ \\
\hline 1 & $\sim 300$ & 1.10 & 2197 & 0.79 & -0.31 & Yes & Over-stocking & Low & Low-High & Necessity & $\mathrm{R}$ & $\begin{array}{l}\text { Inadequate and/or } \\
\text { partial information }\end{array}$ \\
\hline 2 & $\sim 100$ & 1.12 & 2165 & 0.78 & -0.34 & Yes & Over-stocking & High & High-High & Necessity & $\mathrm{P}$ & $\begin{array}{l}\text { Integral information but } \\
\text { lack of capacity }\end{array}$ \\
\hline 3 & $\sim 300$ & 0.90 & 2153 & 0.78 & -0.12 & No & Over-stocking & Low & Low-High & Necessity & $\mathrm{R}$ & $\begin{array}{l}\text { Inadequate and/or } \\
\text { partial information }\end{array}$ \\
\hline 4 & $\sim 300$ & 0.90 & 2216 & 0.80 & -0.10 & No & Over-stocking & Low & Low-High & Necessity & $\mathrm{R}$ & $\begin{array}{l}\text { Inadequate and/or } \\
\text { partial information }\end{array}$ \\
\hline 5 & $\sim 800$ & 0.70 & 1333 & 0.48 & -0.22 & No & Over-stocking & Low & Low-Low & Necessity & $\mathrm{R}$ & $\begin{array}{l}\text { Inadequate and/or } \\
\text { partial information }\end{array}$ \\
\hline 6 & $\sim 300$ & 1.10 & 2204 & 0.79 & -0.31 & Yes & Over-stocking & High & High-High & Necessity & $\mathrm{P}$ & $\begin{array}{l}\text { Integral information but } \\
\text { lack of capacity }\end{array}$ \\
\hline 7 & $\sim 300$ & 0.90 & 1687 & 0.61 & -0.29 & Yes & Over-stocking & High & High-High & Necessity & $\mathrm{P}$ & $\begin{array}{l}\text { Integral information but } \\
\text { lack of capacity }\end{array}$ \\
\hline 8 & $\sim 1000$ & 0.70 & 1900 & 0.68 & -0.02 & No & LSD adjusted & High & High-Low & & & \\
\hline 9 & $\sim 200$ & 0.80 & 2069 & 0.75 & -0.05 & No & LSD adjusted & High & Low-High & & & \\
\hline 10 & $\sim 300$ & 1.02 & 1961 & 0.71 & -0.31 & Yes & Over-stocking & Low & Low-High & Opportunity & G\&R & $\begin{array}{l}\text { Inadequate and/or } \\
\text { partial information } \\
\text { and prioritize the } \\
\text { economic dimension }\end{array}$ \\
\hline 11 & $\sim 300$ & 1.05 & 2169 & 0.78 & -0.27 & Yes & Over-stocking & Low & High-High & Opportunity & G\&R & $\begin{array}{l}\text { Inadequate and/or } \\
\text { partial information } \\
\text { and prioritize the } \\
\text { economic dimension }\end{array}$ \\
\hline 12 & $\sim 300$ & 0.92 & 1987 & 0.72 & -0.20 & Yes & Over-stocking & High & High-High & Necessity & $\mathrm{P}$ & $\begin{array}{l}\text { Integral information but } \\
\text { lack of capacity }\end{array}$ \\
\hline 13 & $\sim 500$ & 1.01 & 2289 & 0.83 & -0.18 & No & Over-stocking & Low & Low-High & Necessity & $\mathrm{R}$ & $\begin{array}{l}\text { Inadequate and/or } \\
\text { partial information }\end{array}$ \\
\hline 14 & $\sim 300$ & 1.00 & 2242 & 0.81 & -0.19 & No & Over-stocking & Low & Low-High & Necessity & $\mathrm{R}$ & $\begin{array}{l}\text { Inadequate and/or } \\
\text { partial information }\end{array}$ \\
\hline 15 & $\sim 300$ & 0.85 & 2088 & 0.75 & -0.10 & Yes & Over-stocking & High & High-High & Necessity & $\mathrm{P}$ & $\begin{array}{l}\text { Integral information but } \\
\text { lack of capacity }\end{array}$ \\
\hline 16 & $\sim 400$ & 1.02 & 2144 & 0.77 & -0.25 & No & Over-stocking & Low & Low-High & Necessity & $\mathrm{R}$ & $\begin{array}{l}\text { Inadequate and/or } \\
\text { partial information }\end{array}$ \\
\hline 17 & $\sim 200$ & 0.71 & 1907 & 0.69 & -0.02 & No & LSD adjusted & High & Low-Low & & & \\
\hline 18 & $\sim 500$ & 0.95 & 1919 & 0.69 & -0.26 & No & Over-stocking & Low & Low-High & Necessity & $\mathrm{R}$ & $\begin{array}{l}\text { Inadequate and/or } \\
\text { partial information }\end{array}$ \\
\hline 19 & $\sim 300$ & 0.94 & 2055 & 0.74 & -0.20 & No & Over-stocking & Low & Low-High & Necessity & $\mathrm{R}$ & $\begin{array}{l}\text { Inadequate and/or } \\
\text { partial information }\end{array}$ \\
\hline 20 & $\sim 200$ & 1.05 & 1597 & 0.58 & -0.47 & Yes & Over-stocking & Low & Low-High & Opportunity & G\&R & $\begin{array}{l}\text { Inadequate and/or } \\
\text { partial information } \\
\text { and prioritize the } \\
\text { economic dimension }\end{array}$ \\
\hline 21 & $\sim 300$ & 0.85 & 2131 & 0.77 & -0.08 & Yes & Over-stocking & High & High-High & Opportunity & G\&R & \\
\hline 22 & $\sim 50$ & 0.95 & 1942 & 0.70 & -0.25 & No & Over-stocking & Low & Low-High & Necessity & $\mathrm{R}$ & $\begin{array}{l}\text { Inadequate and/or } \\
\text { partial information }\end{array}$ \\
\hline 23 & $\sim 50$ & 1.05 & 2124 & 0.77 & -0.28 & Yes & Over-stocking & High & High-High & Necessity & $\mathrm{P}$ & $\begin{array}{l}\text { Integral information but } \\
\text { lack of capacity }\end{array}$ \\
\hline
\end{tabular}


Table 2 (continued)

\begin{tabular}{|c|c|c|c|c|c|c|c|c|c|c|c|c|}
\hline $\begin{array}{l}\text { Producer } \\
\#\end{array}$ & $\begin{array}{l}\text { Farm } \\
\text { area } \\
\text { (ha) }\end{array}$ & $\begin{array}{l}\text { LSD } \\
(\mathrm{LU})\end{array}$ & $\begin{array}{l}\text { UANPP } \\
\text { (DM. } \\
\text { ha }^{-1} \\
\mathrm{y}^{-1} \text { ) }\end{array}$ & $\begin{array}{l}\mathrm{LCC} \\
(\mathrm{LU})\end{array}$ & $\begin{array}{l}\text { LCC- } \\
\text { LSD } \\
(\mathrm{LU})\end{array}$ & $\begin{array}{l}\text { P- } \\
\text { LSD }\end{array}$ & A-LSD & $\begin{array}{l}\text { Perception/ } \\
\text { ANPP } \\
\text { relationship }\end{array}$ & $\begin{array}{l}\text { Perception/ } \\
\text { LSD }\end{array}$ & $\begin{array}{l}\text { Over- } \\
\text { stocking } \\
\text { reason }\end{array}$ & Trap(s) & $\begin{array}{l}\text { Main mechanism for } \\
\text { the trap(s) }\end{array}$ \\
\hline 24 & $\sim 300$ & 0.69 & 1292 & 0.47 & -0.22 & Yes & Over-stocking & High & High-Low & Necessity & $\mathrm{P}$ & $\begin{array}{l}\text { Integral information but } \\
\text { lack of capacity }\end{array}$ \\
\hline 25 & $\sim 500$ & 0.71 & 2224 & 0.80 & 0.09 & No & LSD adjusted & High & High-Low & & & \\
\hline 26 & $\sim 500$ & 0.80 & 1710 & 0.62 & -0.18 & Yes & Over-stocking & High & Low-High & Necessity & $\mathrm{P}$ & $\begin{array}{l}\text { Integral information but } \\
\text { lack of capacity }\end{array}$ \\
\hline 27 & $\sim 300$ & 0.95 & 1872 & 0.67 & -0.28 & Yes & Over-stocking & High & Low-High & Necessity & $\mathrm{P}$ & $\begin{array}{l}\text { Integral information but } \\
\text { lack of capacity }\end{array}$ \\
\hline 28 & $\sim 100$ & 0.95 & 1432 & 0.52 & -0.43 & Yes & Over-stocking & High & Low-High & Necessity & $\mathrm{P}$ & $\begin{array}{l}\text { Integral information but } \\
\text { lack of capacity }\end{array}$ \\
\hline 29 & $\sim 300$ & 1.05 & 1915 & 0.69 & -0.36 & Yes & Over-stocking & Low & Low-High & Opportunity & G\&R & $\begin{array}{l}\text { Inadequate and/or } \\
\text { partial information } \\
\text { and prioritize the } \\
\text { economic dimension }\end{array}$ \\
\hline 30 & $\sim 1000$ & 0.60 & 1523 & 0.55 & -0.05 & No & LSD adjusted & High & High-Low & & & \\
\hline 31 & $\sim 300$ & 0.85 & 1730 & 0.62 & -0.23 & Yes & Over-stocking & Low & High-High & Opportunity & G\&R & $\begin{array}{l}\text { Inadequate and/or } \\
\text { partial information } \\
\text { and prioritize the } \\
\text { economic dimension }\end{array}$ \\
\hline 32 & $\sim 300$ & 1.05 & 2275 & 0.82 & -0.23 & Yes & Over-stocking & High & High-High & Necessity & $\mathrm{P}$ & $\begin{array}{l}\text { Integral information but } \\
\text { lack of capacity }\end{array}$ \\
\hline 33 & $\sim 1200$ & 0.62 & 1750 & 0.63 & 0.01 & No & LSD adjusted & High & High-Low & & & \\
\hline 34 & $\sim 1500$ & 0.60 & 2234 & 0.81 & 0.21 & No & LSD adjusted & High & High-Low & & & \\
\hline 35 & $\sim 1500$ & 0.61 & 2204 & 0.79 & 0.18 & No & LSD adjusted & High & High-Low & & & \\
\hline
\end{tabular}

In cases of more than one trap, the order does not necessarily imply that one trap is more important than or precedes the other. Inadequate and/or partial information refers to one or more than the following three situations: non incorporation of key information, key information not considered, and inadequate weighting of available information. Integral information refers to the opposite to the inadequate and/or partial information

to or lower than that of the LCC, more than $75 \%$ confirmed that their grassland had a very high productivity (e.g., farmers 8,25 , and 33). Some livestock farmers whose perceived grassland productivity was not high also perceived that they could increase the stocking density (e.g., farmers 5 and 17). In total, $46 \%$ of livestock farmers perceived grassland productivity as low, and $17 \%$ of livestock farmers perceived grassland productivity as high resorted to over-stocking. In addition, more than half of the latter showed ANPP values lower than the mean for the area. Although farms with over-stocking prevailed, the difference between adjusted and unadjusted stocking density was greater in the farms with the pastures perceived as having lower productivity.

Proposals to reduce vulnerability to drought presented by researchers and public policy makers agree with the need to adjust the stocking density to the grassland conditions (Bartaburu et al. 2009, 2013). However, this strategy is not adopted by most livestock farmers in the area (Table 2) for three main reasons that determine this situation: inadequate and/or partial information, impossibility of changing the current strategy, and, lastly, selection of another strategy. The first case, which shows the existence of rigidity traps (Carpenter and Brock 2008), is based on empirical evidence suggesting that many livestock farmers use the over-stocking strategy without being fully aware of the responses of their grasslands and of the potential medium-term impacts. These decisions are mainly influenced by the inability to incorporate currently available information into their decision-making processes which is aggravated by the rigidity of the system and by the lack of rural extension. The second case, which highlights the existence of poverty traps according to the definition of Carpenter and Brock (2008), is based on the unfeasibility or lack of implementation of currently proposed strategies owing to the livestock farmers' structural conditions, particularly availability of capital to modify their production system, as well as their age and possibility of increased working hours, among other factors. Relevant practices, such as paddock design, improvement of availability of water and shade, as well as management of the herd, require investment and an increase of the working hours into the farm. 
The third case, which highlights the existence of gilded traps (Steneck et al. 2011), corresponds to a set of livestock farmers who resort to over-stocking because they identify an economic opportunity, prioritizing these benefits over other structural and long-term benefits. These farmers decide to resort overstocking but also overvalued the grasslands. Not only these farmers affected by a gilded trap (regardless of whether overstocking determines high or higher revenues) but also other livestock farmers make this decision to maintain the current situation and not for an exclusively economic purpose.

Identifying the vulnerability of the system and the actions necessary to reduce this vulnerability are two fundamental obstacles that must be overcome in order to move toward successful adaptation processes. This requires, first, overcoming the barriers that hinder or prevent adaptation (Moser and Ekstrom 2010). An important set of these barriers occurs in the first phase of the adaptation process, which refers to understanding the problem in three stages: detecting the problem, gathering/using information, and (re)defining the problem (Moser and Ekstrom 2010). It is evident that a significant fraction of the farmers analyzed in this study, for various reasons, fail to overcome the first stage of the first phase. This situation further increases the high level of vulnerability to drought of livestock farmers in areas of high exposure and high sensitivity, as highlighted by Díaz et al. (2018, 2019). Furthermore, the absence of information makes it impossible to efficiently develop at least the first (planning) and third (observation/control) management stages of all crop and livestock production systems (Cros et al. 2004).

\subsection{Traps in grassland management}

Livestock farmers with a high perceived grassland productivity and who used an LSD adjusted to grassland productivity $(n=7)$ were mostly those who managed the largest farms in the study area. Livestock farmers with a low perceived grassland productivity and who used an LSD adjusted to grassland productivity $(n=1)$ were family livestock farmers with low levels of vulnerability to drought. Livestock farmers with a high perceived grassland productivity and who resorted to over-stocking $(n=$ 11) were family and small-scale livestock farmers, as well as, for very different reasons, small-scale livestock farmers with high levels of education and who often used dietary supplementation. Lastly, livestock farmers with a low perceived grassland productivity and who resorted to over-stocking $(n=16)$ formed a very heterogeneous group of livestock farmers in terms of farm size and stocking density. In total, $23 \%$ of livestock farmers were unaffected by any trap. Conversely, $31 \%, 17 \%$, and $43 \%$ of livestock farmers were affected by poverty traps, gilded traps, and rigidity traps, respectively (Table 2 ). In addition, $14 \%$ were simultaneously affected by gilded and rigidity traps. Thus, 5 situations were prominent: (a) 11 livestock farmers affected by poverty traps, (b) 10 livestock farmers affected by rigidity traps, (c) 5 livestock farmers affected by gilded and rigidity traps, (d) 1 livestock farmer affected by gilded traps, and (e) 8 livestock farmers unaffected by any of the three traps analyzed in this study.

The findings allow us to identify and differentiate livestock farmer groups to define knowledge dissemination and/or generation activities. A priority group is formed by livestock farmers affected by poverty traps, among whom alternatives cannot be implemented for economic reasons (Díaz et al. 2018). Skills must be developed and applied to increase the response through the development of low-cost strategies already consolidated in Uruguay (Pereira 2003; Carriquiry and Fernandez 2004). Accordingly, agricultural institutions play a key role in this regard. A policy that integrates all the agents, a broad vision considering different paradigms, the search for flexibility, and coordination are challenges posed by Mondelli and Picasso (2001) that are still valid. Furthermore, for livestock farmers who manage small farms and/or lease agricultural land at high costs, the above strategies should be supplemented with access to land. If not, they will not be able to avoid the trap only through improvements in the management of the activity. In addition, economic measures that facilitate the transition to short- and long-term sustainable management strategies should also be investigated. Among these livestock farmers, and those in rigidity traps, the problems identified by Bartaburu et al. (2009) worsen in periods of drought (in reference to the "perverse cycle of the producer" that increases the LSD in favorable climatic conditions and retains the cattle in unfavorable conditions or sells them at low prices, with the consequences that this behavior implies in its capital, in its production, and in the degradation of the natural grassland). This cycle increases their vulnerability because droughts affect sensitivity and limit the future development of adaptability. Another priority group corresponds to farmers who show rigidity traps (e.g., over-stocking and high perceived grassland productivity). For these livestock farmers, the development of skills is key because innovations are available, but their dissemination and promotion are limited; hence, the main obstacle is access to and understanding of information (Díaz et al. 2018). Therefore, the central problem is the acquisition and assimilation of information, which 
highlights the need for rethinking dissemination strategies, especially considering investment is generally not a determining factor and that the economic benefits from its current over-stocking strategy have been questioned in the region (Albicette et al. 2017). Because the decisions of livestock farmers affected by gilded traps are strictly made for maximization of profit, the priority must be to further the evaluation of the economic and environmental benefits, at diverse spatial and temporal scales, from adjusting the stocking density. According to Steneck et al. (2011), escaping from gilded traps requires new resource management structures and policies. Accordingly, another major challenge is the incorporation of the concept and regulations on the sustainable use of natural resources (primarily soil and water) that have been developed in agricultural crop in recent years in Uruguay into livestock production.

The system under study differs from the model proposed by Carpenter and Brock (2008) with its additional complexity, thereby requiring other strategies. First is the existence of a new (gilded) trap, in addition to that of poverty and rigidity traps. This situation raises the question as to whether the simultaneous existence of two traps is more harmful than the existence of a single trap or, more simply, whether a livestock farmer affected by the gilded and poverty trap is closer to an adaptation phase or to disappearing from the system than a livestock farmer only affected by rigidity traps. The second emerges as a question if livestock farmers can leave the system only from rigidity traps. Specifically for Uruguay, and particularly for the study area, empirical evidence based on official data (DIEA 2011) supports the hypothesis that livestock farmers who leave the system are actually those with characteristics specific of poverty traps, because those who disappear from the system are primarily small-scale livestock farmers (note that between 2000 and 2011, 12,241 farms have disappeared, being the $91 \%$ of the farm less than 100 ha). Lastly, livestock farmers affected by poverty traps, as well as rigidity traps, albeit to a smaller extent (e.g., livestock farmers who not only fail to correctly assess their grasslands but also knowingly resort to over-stocking because they cannot adapt their production system for economic reasons) were identified in the study area. These livestock farmers, who would be in a more stable situation in the scheme proposed by Carpenter and Brock (2008) for being between two traps (adaptation or reconfiguration process without leaving the system), could eventually find themselves in a worse situation in a context where they could be expelled from the system by any trap. Future studies should further investigate the relationship between traps and the context in which they develop and consolidate mainly to understand how they are linked to and influence decisionmaking.

The analyzed temporal period allowed to identify the general patterns in the decisions of the producers and the traps that compromise the sustainability of the farms. Increasing temporal and spatial scale would contribute to further deepening of the link between traps, vulnerability, and sustainability in the management of natural grasslands. Additionally, having more extensive series of data would greatly contribute to deepening the identification and characterization of the traps. Although remote sensing techniques contribute in this way, availability of data does not allow capturing the entire grassland history and demands to be cautious in the interpretation of the results. In the same way, that what happens with the productive history of the farmers, due to the fact that they do not have systematized information of their evaluations, strategies, and decisions.

\section{Conclusion}

This study shows for the first time that the decisionmaking of the Uruguayan livestock farmers about the natural grassland's management is determinate by poverty, rigidity, and gilded traps. This adverse configuration favors the increase of its vulnerability and compromises its sustainability.

Over-stocking is a strategy commonly used by many livestock farmers to maintain their capital whether they know or ignore the associated risks. However, a considerable number of livestock farmers perceived their grassland productivity as higher than the productivity estimated using empirical methods and that they could maintain high stocking densities. These livestock farmers, who fail to overcome the first phase of adaptation barriers and who face severe traps, are more sensitive to drought. They require, to a greater extent, concrete actions to end the current adverse situation. As long as they maintain this over-stocking strategy, their levels of vulnerability will progressively increase.

The efforts devoted to highlighting the advantages of considering stocking density, a central management variable, through public policies and dissemination strategies remain insufficient to reverse historically consolidated traps. In addition, differences between the perception of livestock farmers and technical estimates of productivity generate a new obstacle. 
This study advances our understanding of livestock production systems of Sierras del Este and may be very useful for decision-makers. Nevertheless, estimation of ANPP, spatiotemporal variability to nutritional and harvest requirements, and the behavior of all these variables in periods of drought, as well as that of the livestock farmers' strategies, decisions, and objectives, must be improved. Among these aspects, the spatiotemporal scale must be increased to plan farm management. Improving these evaluations and the understanding of the traps that constrain the livestock farmers' decision-making process is the key to not compromising the sustainability of agroecosystems.

Acknowledgments The authors express their gratitude to the cattle farmers who participated in the interviews. Also, the authors are grateful to the four anonymous reviewers and the editor for their comments that greatly improved this paper.

Funding information This research has been carried out with financial support from the Comisión Académica de Posgrado de la Universidad de la República (CAP-UDELAR).

Data availability The datasets generated during and/or analyzed during the current study are available from the corresponding author on reasonable request.

\section{Compliance with ethical standards}

Conflict of interest The authors declare that they have no conflict of interest.

\section{References}

AFRC (1993) Energy and protein requirements of ruminants. An advisory manual prepared by the AFRC technical committee on responses to nutrients. CAB International, Wallingford, United Kingdom

Albicette MM, Leoni C, Ruggia A et al (2017) Co-innovation in familyfarming livestock systems in Rocha. A 3-year learning process. Outlook Agric, Uruguay. https://doi.org/10.1177/ 0030727017707407

Baeza S, Paruelo J, Ayala W (2011) Eficiencia en el uso de la radiación y productividad primaria en recursos forrajeros del este de Uruguay. Agrociencia 15:48-49

Bartaburu D, Duarte E, Montes E et al (2009) Las sequías: un evento que afecta la trayectoria de las empresas y su gente. In: Familias y campo. Rescatando estrategias de adaptación. IPA, Montevideo, pp $155-168$

Bartaburu D, Morales H, Dieguez F et al (2013) Sensibilidad y capacidad adaptativa de la ganadería frente al cambio climático. In: Clima de cambios: nuevos desafíos de adaptación en Uruguay. FAO TCP URU 3302. Montevideo, Montevideo, p 58

Carpenter S, Brock W (2008) Adaptive capacity and traps. Ecol Soc 13. https://doi.org/10.5751/ES-02716-130240
Carriquiry M, Fernandez A (2004) Adopción de una tecnología por productores ganaderos de Rocha. Tesis Ing. Agr. Montev. Universidad de la República, Universidad de la República

Cosens B, Gunderson L (2018) An introduction to practical panarchy: linking law, resilience, and adaptive water governance of regional scale social-ecological systems. In: Cosens B, Gunderson L (eds) Practical panarchy for adaptive water governance. Linking Law to Social-Ecological Resilience, Springer, Cham, p 332

Cros MJ, Duru M, Garcia F, Martin-Clouaire R (2004) Simulating management strategies: the rotational grazing example. Agric Syst 80: 23-42. https://doi.org/10.1016/j.agsy.2003.06.001

Díaz I, Achkar M, Mazzeo N (2018) Drought vulnerability assessment of cattle producers in the Sierras del Este-Uruguay: interactions between actors and agents. Outlook Agric 47:315-325. https://doi. org/10.1177/0030727018808807

Díaz I, Achkar M, Crisci C, Mazzeo N (2019) Natural and land-use drivers of primary production in a highly vulnerable region of livestock production. J Agric Rural Dev Trop Subtrop 120:1-14. https:// doi.org/10.17170/kobra-20190219194

DIEA (2011) Censo General Agropecuario. Resultados definitivos, Montevideo

Do Carmo M, Claramunt M, Carriquiry M, Soca P (2016) Animal energetics in extensive grazing systems: rationality and results of research models to improve energy efficiency of beef cow-calf grazing Campos systems. J Anim Sci 94:84-92. https://doi.org/10.2527/jas. 2016-0596

Foran BD, Stafford DM (1991) Risk, biology and drought management strategies for cattle stations in Central Australia. J Environ Manag 33:17-33. https://doi.org/10.1016/S0301-4797(05)80045-3

Gallego F, Lezama F, Pezzani F et al (2017) Estimación de la productividad primaria neta aérea y capacidad de carga ganadera: un estudio de caso en Sierras del Este, Uruguay. Agrociencia Uruguay 21:120-130

Gunderson L, Holling CS (2002) Panarchy synopsis: understanding transformations in human and natural systems

Gutierrez R, Modernel P (2011) Los procesos de adopción y manejo tecnológico en la producción familiar criadora. Rev del Plan Agropecu 140:60-63

Haider LJ, Boonstra WJ, Peterson GD, Schlüter M (2018) Traps and sustainable development in rural areas: a review. World Dev. https://doi.org/10.1016/j.worlddev.2017.05.038

INIA (2012) Revisión y análisis de las bases históricas y científicas del uso de la equivalencia ovino:bovino. Montevideo

Kemp DR, Michalk DL (2007) Towards sustainable grassland and livestock management. J Agric Sci 145:543-564. https://doi.org/10. 1017/S0021859607007253

Lindemann T, Plata V, Oyhantçabal W, Sancho D (2013) La percepción de productores y técnicos agropecuarios. Clima de cambios: Nuevos desafíos de adaptación para Uruguay, MGAP FAO Rep., Vol. 2, 95 pp.,. In: Clima de cambios: nuevos desafíos de adaptación en Uruguay. p 95

McKeon GM, Stone GS, Syktus JI et al (2009) Climate change impacts on northern Australian rangeland livestock carrying capacity: a review of issues. Rangel J 31:1-29. https://doi.org/10.1071/RJ08068

Mondelli M, Picasso V (2001) Trayectorias tecnológicas en la ganadería uruguaya: un enfoque evolucionista. Universidad de la República

Monteith JL (1972) Solar radiation and productivity in tropical ecosystems. J Appl Ecol 9:747-766. https://doi.org/10.2307/2401901

Moser SC, Ekstrom JA (2010) A framework to diagnose barriers to climate change adaptation. Proc Natl Acad Sci 107:22026-22031. https://doi.org/10.1073/pnas.1007887107 
Pereira G (2003) La ganadería en Uruguay, contribución a su conocimiento. Montevideo

Steneck RS, Hughes TP, Cinner JE et al (2011) Creation of a gilded trap by the high economic value of the Maine lobster fishery. Conserv Biol. https://doi.org/10.1111/j.1523-1739.2011.01717.x

Tittonell P (2014) Livelihood strategies, resilience and transformability in African agroecosystems. Agric Syst 126:3-14. https://doi.org/10. 1016/j.agsy.2013.10.010
Westley F, Zimmerman B, Patton M (2006) Getting to maybe: how the world has changed. Ontario, Canada

Zhang YJ, Zhang XQ, Wang XY et al (2014) Establishing the carrying capacity of the grasslands of China: a review. Rangel J 36:1-9. https://doi.org/10.1071/RJ13033

Publisher's note Springer Nature remains neutral with regard to jurisdictional claims in published maps and institutional affiliations. 